\title{
Student-Centered Online Teaching Practices in Theoretical Mechanics
}

\author{
Haibin Sun ${ }^{1} \&$ Tingting Liu ${ }^{1}$ \\ ${ }^{1}$ College of Physics and Electronic Engineering, Taishan University, Tai'an, Shandong, 271000, China \\ Correspondence: Haibin Sun, College of Physics and Electronic Engineering, Taishan University, Tai'an, \\ Shandong, China. E-mail: sunhbphy@tsu.edu.cn
}

$\begin{array}{lcc}\text { Received: April 2, } 2021 & \text { Accepted: May 3, } 2021 & \text { Online Published: May 7, } 2021 \\ \text { doi:10.5539/hes.v11n2p233 } & \text { URL: https://doi.org/10.5539/hes.v11n2p233 }\end{array}$

\begin{abstract}
The COVID-19 pandemic has had a serious impact on education at all levels and types, and the education system, including colleges and universities, has been forced to respond by a sudden shift to online teaching. Successful online teaching requires careful thinking, planning, and technical and human support from teachers. Based on the reflection on the offline classroom teaching of theoretical mechanics for many years and the online teaching practice of first half of 2020, the author summarizes effective strategies for implementing online teaching of theoretical mechanics. We prepared the theoretical mechanical lessons through a "student-centered" approach, such as preparing teaching materials, students and teaching methods. These teaching strategies include (i) Adopting live-stream teaching as the main teaching method, (ii) Applying electronic blackboard to online deductions, (iii) Linking theory to practice for better understanding of knowledge, (iv) Integrating curriculum content in ideological and moral education, (v) Conducting formative assessment to supervise and motivate online learning. The implementation of these online teaching strategies has effectively promoted the development of students' independent learning ability.
\end{abstract}

Keywords: student-centered, online teaching, theoretical mechanics, learning ability

\section{Introduction}

Large-scale online teaching amid the novel coronavirus (COVID-19) epidemic has put forward new demands and challenges for both teachers and students all over the world (Gewin, 2020; Sintema, 2020; Usak, Masalimova, Cherdymova, \& Shaidullina, 2020). Undoubtedly, the purpose of both online and traditional offline teaching is to promote the all-round development of college students, thus helping them establish a proper outlook in career and life, correct values and worldview, and the comprehensive qualities and capacity for lifelong learning (Xie, Qiu, Huang, \& Wang, 2020). Online teaching can be carried out through online platforms in the form of live streaming or pre-recorded videos. Irrespective of its form, however, its effectiveness depends largely on students' consciousness of independent learning and learning habits. It calls for teachers to adopt a "student-centered" approach to stimulate students' interest and motivation in independent learning, using a variety of teaching methods and to delegate more power to students for practice, feedback (Komatsu, Rappleye, \& Silova, 2021).

The field of higher education pays more and more attention to the "student-centered" educational philosophy. Student-centered pedagogy is the main point of constructivist learning theory. Constructivist learning theory believes that knowledge is constructed by learners based on different psychological structures and social experiences, emphasizing the initiative, contextuality and sociality of learning. Learners can construct meaning based on their experience and the learning environment itself (Parrish \& Sadera, 2018). Student-centered education provides learners with opportunities for personal participation in all teaching activities, and considers personal characteristics, so that students learn to learn, learn to acquire and apply knowledge, and promote the development of students' scientific thinking and communication skills (Akdemir \& Özçelik, 2019). Studies have shown that student-centered science teaching method is considered to be linearly positively correlated with students' academic performance in science teaching (Bara \& Xhomara, 2020). The student-centeredness is different from the traditional classroom teaching model centered on "textbooks, teachers, and classrooms". Students are the main body of teaching activities. The purpose of student-centered education is to learn, but not to teach (Wang, Cui, \& Yan, 2020).

At the end of 2018, the Ministry of Education of the People's Republic of China stated in the Opinion on 
Accelerating the Construction of High-level Undergraduate Education to Comprehensively Improve Talent Cultivation Capacity, the need to "adhere to student-centered and all-round development" for promoting the construction of high-level and -quality higher education (Ministry of Education of the People's Republic of China, 2018). To smoothly implement teaching tasks in theoretical mechanics during the current semester, online teaching was carried out using DingTalk as the primary platform and QQ as the secondary. A summary of online teaching practices throughout the semester concluded that to improve the quality of online teaching, it is important to fully realize the dominant position of students and employ teaching practices that are "student-centered and student development-oriented." Based on the practices and reflection of the online teaching of theoretical mechanics, this paper discusses the "student-centered" lesson preparation activities in terms of teaching materials and methods, students, and the "student development-oriented" strategies of online teaching adopted throughout the semester.

\section{Student-Centered Lesson Preparation in Theoretical Mechanics}

Lesson preparation is an important cornerstone that ensures smooth classroom teaching and realization of teaching objectives and serves as a requisite for improved teaching quality. From the perspective of teachers' professional development, lesson preparation is also a process during which teachers improve their teaching skills and professional competencies. The implementation of online teaching has imposed higher demands on lesson preparation among teachers. Lesson preparation mainly concerns the preparation of teaching materials, students, and teaching methods. Online teaching requires teachers to update their ways of thinking and pedagogical philosophy, broaden their knowledge of lesson preparation, and prepare their lessons through a "student-centered" approach.

\subsection{Preparing the Teaching Materials}

This paper analyzed and studied the teaching materials by scrutinizing the talent development plan and course outline, in order to understand the intention of compiling the teaching materials and clarifying the specific requirements for teaching. The textbook used in this course was A Course in Theoretical Mechanics (Zhou, 2018), edited by Zhou YanBai, a classic for teaching physics. During the preparation of the teaching materials, references were also made to the textbooks compiled by Goldstein Herbert (Goldstein, Poole, \& Safko, 2005). Through analysis of the teaching materials, we grasped the logical structure of the knowledge involved and identified the priorities and difficulties in teaching, the main applications of the knowledge, and the elements of ideological education. During the preparation, careful calculation and analysis were performed on all the exercises in the teaching materials, which were classified into problems with multiple solutions, problems with the same solution, and other categories. We analyzed the degree of difficulty of each exercise, its intention and purpose, and the timing when exercises were assigned. A number of practice-focused exercises pertaining to relevant knowledge were also incorporated to allow for the selective assignment of exercises during the teaching process.

For example, when we teach "Instantaneous center of zero velocity of rigid body in the plane motion", Example 1 (movement of elliptical ruler) on page 136 of the textbook and Exercise 3.15 (plane parallel motion of rectangular plate) on page 162 of the textbook belong to the same type of problems. It is to use the velocity direction of two points to determine the location of the instantaneous center. Exercise 3.16 on page 162 of the textbook is to calculate the velocity of any point on the edge of the non-slip rolling wheel, which can be solved by two different methods: the base point method and the instantaneous center method. After learning the knowledge of instantaneous center, the teacher guides the students to analyze the rotation of table tennis, so as to consolidate the knowledge and develop the thinking ability.

\subsection{Preparing the Students}

Teaching and learning are bilateral activities, and the effectiveness of teaching is tied to cooperation on the students' part. In both online and offline teaching, students are the main subjects in the classroom. A teacher can yield better teaching outcomes if he/she is good at understanding the students and is able to perform heuristic teaching based on their actual conditions and give full play to their initiative. Hence, an in-depth understanding of the students is an indispensable part of lesson preparation. Before learning theoretical mechanics, students have systematically studied mechanics and advanced mathematics. They have a solid grasp of the physics concepts and laws related to mechanics, and can use the knowledge they have learned to analyze mechanics problems. Mechanics courses basically start from physics phenomena, through analysis and induction methods, to derive the empirical laws of material movement, emphasizing the cognitive process from perceptual to rational. Theoretical mechanics starts from the empirical laws of physics, creates a rational physics world, and then uses logical deduction to infer the various properties that this rational world should have, and then compares 
it with actual empirical facts. To check the authenticity and explore the possibility of its practical application. Therefore, the study of theoretical mechanics has higher requirements for students' abstract thinking ability, spatial imagination ability and the ability to apply advanced mathematics knowledge to solve problems. Some students may not adapt well and cause thinking obstacles and learning difficulties.

Based on the general background of online teaching, a learner analysis was conducted to fully inspect the cognitive characteristics and patterns, basic knowledge, capabilities, and psychological conditions of the target students (i.e., year two college students majoring in physics) and analyze and predict the reasons that they might experience confusion and encounter obstacles at school. This aimed to find the right antidotes for solving students' learning difficulties during teaching practices. Given that the students were studying at home and lacked access to learning materials, materials closely related to the course were uploaded to the course group in advance, such as electronic versions of teaching materials provided by publishers, courseware, popular science and English literature on mechanics, and topics in mechanics competitions for college students. This not only facilitated the students' independent learning but also eased the limitations they faced in terms of wireless data usage. Figure 1 is part of the learning materials we provide for students' online learning.
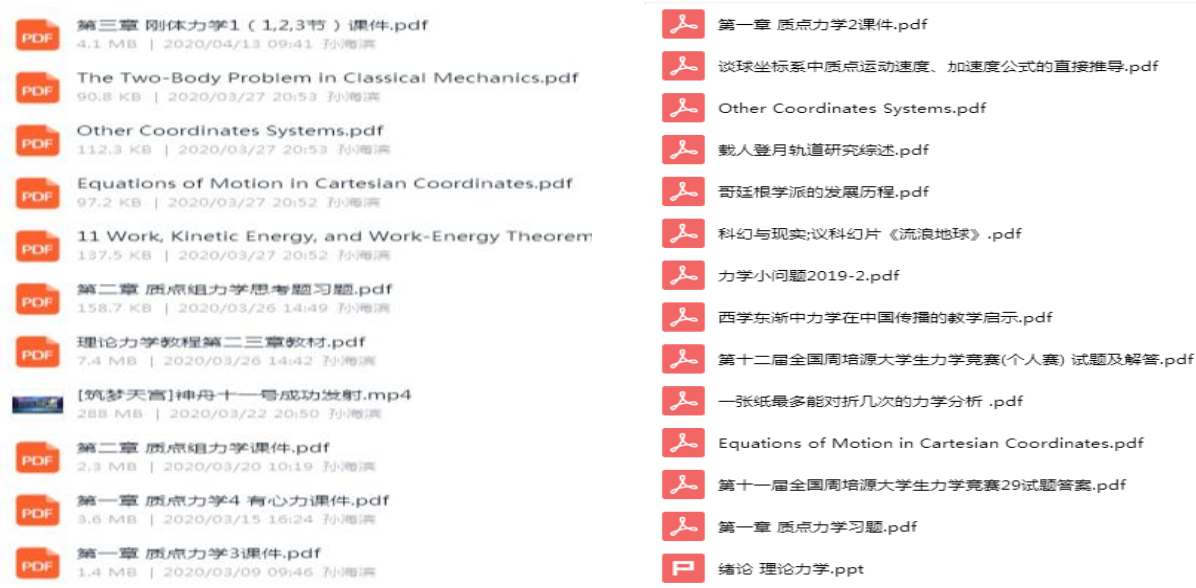

Figure 1. Learning materials of the theoretical mechanics online course group

With the advancement and deepening of online teaching, timely recommendations were made to introduce students to selected online course resources in the course group, such as the course resources on the Chinese University MOOC platform, a micro-lecture series called "Yunli, Wuli" from the Institute of Physics of the Chinese Academy of Sciences, and related resources on ScienceNet.cn. These resources allowed overachieving students to watch and browse supplementary materials in their spare time, self-study professional knowledge, expand their professional horizons, and improve their knowledge in the field of physics.

\subsection{Preparing the Teaching Methods}

The preparation of the teaching methods was an endeavor to choose the ideal approaches that facilitated both online and offline self-study according to the course objectives, pedagogical goals, teaching content, and students' characteristics; it was intended to impart the teaching content fully and satisfactorily to students within a prescribed timeframe. The selection of teaching methods was not a narrow pursuit of formality. Rather, it emphasized practicality and sought to motivate all students to take the initiative in learning the course. When designing the teaching plan, the focus was on how to stimulate students' thinking, give them more time and leeway for independent learning, reflection, and exchanges, and avoid the over-cramming of online teaching content and a frenetic teaching pace. We also strived to design PowerPoint courseware with clearly defined layers and elaboration on the key and difficult points in as much detail as possible, so as to help students' online learning and offline revision, as shown in Figure 2. For the key and difficult knowledge, questions and test items were prepared in advance for use in online teaching.

During the above three processes of preparation, we carefully developed a lesson plan and established a course resource library for theoretical mechanics based on years of teaching experience. The resource library included materials such as talent development plans, course outlines, courseware, lesson plans, instructional videos, learner analyses, sets of exercises, test items, animation libraries, picture and video libraries, and historical materials on mechanics. Moderate selection and development of extended course resources in theoretical 
mechanics can render students' independent learning more holistic, systematic, and challenging.
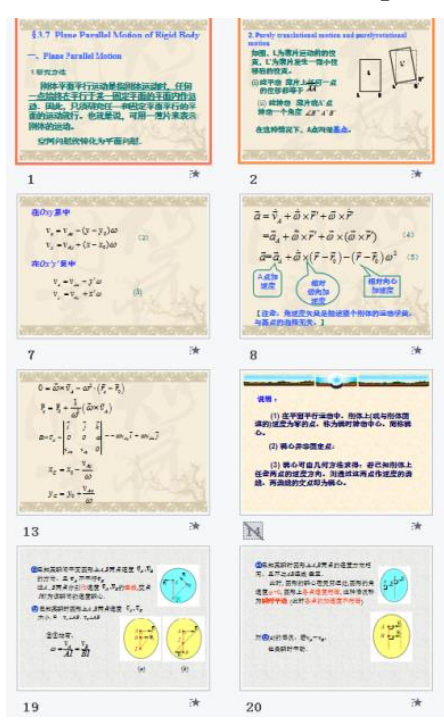

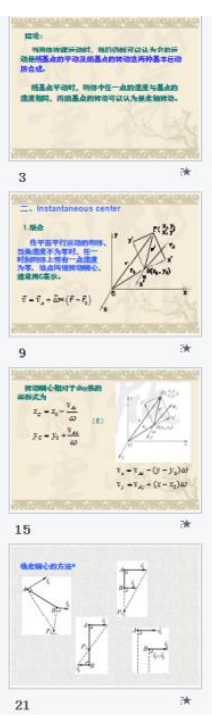

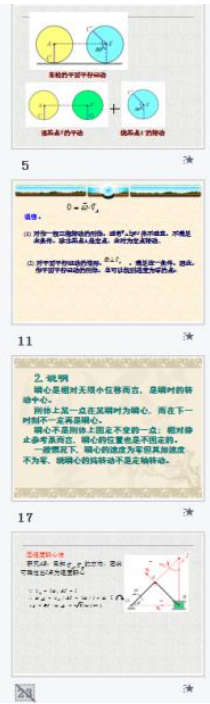

Figure 2. PowerPoint courseware of $\$ 3.7$

\section{3. "Student Development-Oriented" Strategies of Online Teaching in Theoretical Mechanics}

In both traditional offline classroom teaching and the current model of online teaching, students serve as the main subjects of teaching, the process of which is guided by teachers. Therefore, teachers should follow students' cognitive patterns when carrying out teaching activities to guide their active and independent learning( $\mathrm{Wu}$, Zhu, \& Huang, 2019). As the development of students' cognitive thinking and creative abilities, as well as their professional competencies, is a key concern in online teaching, "student-led learning" becomes its main focus. The vision of "suspending classes without suspending teaching and learning" places the emphasis on how teachers "teach" and translate "teaching" into students' independent learning. Thus, the online teaching of theoretical mechanics was heavily oriented towards "student development" and focused on the development of students' independent learning skills. The strategies adopted during the teaching process are summarized as follows.

\subsection{Adopting Live-Stream Teaching as the Main Teaching Method}

To avoid frequent switching between teaching platforms over the duration of the course, preliminary research and broadcasting trials were conducted. DingTalk was chosen as the platform for live-stream teaching to ensure the stable quality of online teaching. Screen recordings were also prepared as a contingency against emergencies. As DingTalk groups offered features such as attendance taking, tests, discussions, release of assignments, live streaming, and playback (including live-stream statistics and data analysis), the platform fully met the needs of online teaching. The advantage of live-stream teaching is its close resemblance to classroom teaching in real life, which allows it to fully engage students in reflective activities. Without disrupting the pace of teaching, students could ask questions, give immediate feedback, and interact with teachers in real time, using superimposed comments scrolling across the frame. Through their feedback, teachers could also gain immediate understanding of their learning status, learning outcomes and difficulties, and make the necessary adjustments to the teaching content and methods. In addition, the live streams could be re-watched by students with learning needs, in order to clarify the points that they failed to grasp in class.

\subsection{Applying Electronic Blackboard to Online Deductions}

Due to the theoretical nature of knowledge in theoretical mechanics, teaching entails considerable derivation of formulas. During the live-stream sessions, digital writing pads were employed to derive formulas elaborately in the blank spaces (or reserved blank pages) of PowerPoint presentations or using the DingTalk whiteboard. This essentially transformed the computer screen into a "blackboard" and simple courseware presentations into electronic blackboard lectures aided by multimedia courseware, as shown in Figure 3. The use of electronic blackboard in live-stream teaching could engage students in learning experiences that were closer to offline classroom teaching, while stimulating and giving play to their interest and initiative in learning. It also improved students' attention and inspired and guided their reflective activities, thereby improving the quality of online 
teaching.

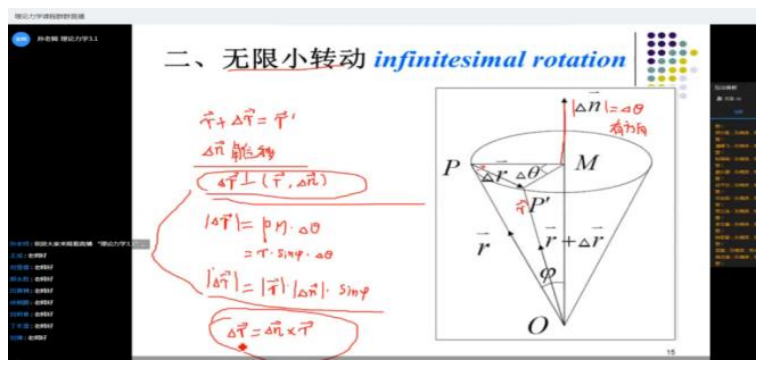

Fugure 3. Online explanation of infinite rotation on the blackboard

\subsection{Linking Theory to Practice for Better Understanding of Knowledge}

As a subject in theoretical physics, theoretical mechanics entails highly abstract knowledge, but it is also linked with a wide spectrum of practical and life-related topics from actual production technology to physical phenomena seen in everyday life and the socio-economic problems related to physics. During the course of teaching, mechanical problems related to the real world, such as how to use the principle of minimum potential energy to analyze the site selection of rural elementary schools (The potential energy of the system should be minimized at equilibrium ), why children fall easily (The time it takes for the rod to fall under gravity ), what keeps bicycles from falling (moment of momentum $\vec{L}=\vec{r} \times m \vec{v}$ ), river bank erosion (Coriolis force $\left.-2 m \vec{\omega} \times \vec{v}^{\prime}\right)$, and the wear and tear of railway tracks, were carefully selected for analysis and discussion. In short, drawing links to the real world and everyday life in online teaching could arouse students' interest in learning and curiosity, guide their active thinking, and improve their understanding and grasp of knowledge. At the same time, students could learn to identify problems in the real world and apply mechanical knowledge to analyze and solve real-life problems. The linkage between theory and practice in online teaching helped students to develop the ability to explain phenomena and solve practical problems using what they had learned, stimulated their creativity, and gave them an insight into the relationship between science, technology, and society.

\subsection{Integrating Curriculum Content in Ideological and Moral Education}

Theoretical mechanics courses are rich in ideological and political elements. In the teaching process, effective teaching methods can be adopted to combine these elements with knowledge in theoretical mechanics organically, subconsciously instilling scientific attitude and spirit, volitional qualities, and patriotic sentiments into students and influencing them subliminally through the development of mechanical concepts, derivation of mechanical laws, and analysis of mechanical phenomena. In addition to having the first class of the school year themed around epidemic prevention and control, the history of theoretical mechanics and other topics were also incorporated in the teaching process for subconscious ideological and political education. For example, in terms of central force and the two-body problem, Newton's creative contributions during the Great Plague of London, China's achievements in manned spaceflight, and the inspiring stories of scientists such as Deng JiaXian, Qian XueSen, Guo YongHuai, and Huang DaNian were introduced. A video of the successful launch of the ShenZhou-11 manned spacecraft, videos documenting scientists' stories, and related literature were also pushed to the students.

\subsection{Conducting Formative Assessment to Supervise and Motivate Online Learning}

Formative assessment mainly examines whether students have completed the staged learning tasks and their attitudes towards learning (Nieminen, Hähkiöniemi \& Viiri, 2020). Through formative assessment, teachers can keep abreast of students' learning status and obtain continuous feedback, which makes it easier to adjust their teaching plans, improve the teaching methods, and enhance the quality of online teaching (Klein et al.,2021).

The main forms of formative assessment adopted during the process of online teaching were as follows: checking class notes, classroom questioning, in-class exercises and in-class quizzes.

Checking class notes: Notetaking during online classes helped students stabilize their attention and keep up with the teacher's train of thought. It was conducive to accumulating learning materials and reinforcing the understanding, revision, and memory of the learning content. Checking students' class notes allowed teachers to examine students' understanding and reflect on whether the teaching objectives were realistic for them. Figure 4 
is a class note submitted by a student. The student's notes are written carefully and rich in content, indicating that the student attends the class seriously.

Classroom questioning: When designing the teaching plan, questions were devised in advance in relation to important knowledge or asked according to students' feedback during online teaching. Students who paid attention in the class could easily answer these questions in one or two sentences, after a short period of deliberation. Students tended to show great initiative in answering such questions.

In-class exercises: After the completion of a live-stream session or a certain learning module, students were assigned an in-class exercise that would take five to ten minutes. They could leave comments or answer the questions using the microphone.

In-class quizzes: Students were asked to take pictures and submit their answers within a certain time limit. In-class questioning and tests pertaining to carefully selected knowledge were conducted to not only consolidate the knowledge learned but also examine the students' learning status and supervise and motivate online learning. For students who were unable to understand some of the information taught in the online class, targeted one-to-one Q\&A and tutoring sessions were provided after class. Assignments were assigned flexibly according to the students' online performance and feedback. This not only stimulated their initiative in learning but also helped them better understand and grasp the information learned, ensuring the improved quality of learning of the class collectively.

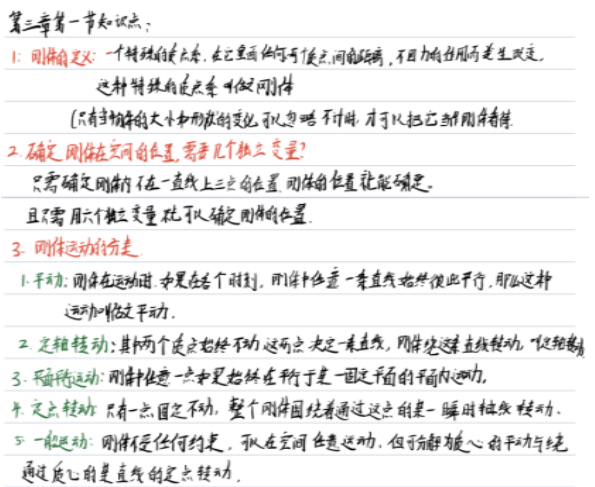

Figure 4. Class notes submitted by a student

\section{Final Comments}

In summary, online teaching that is predominantly home-based will undoubtedly continue to affect the traditional model of teaching. Even when university teaching returns to the traditional classroom after the epidemic, teachers and students will definitely view and improve the traditional teaching methods based on their new experiences and from a new perspective. Insofar as the pedagogical philosophy of "student-centered and student development-oriented" education and the noble cause of "teaching knowledge and cultivating the person" are upheld, combined with the adoption of scientific and sensible teaching strategies, satisfactory teaching outcomes are bound to transpire.

\section{Acknowledgments}

This work has been supported by the Teaching Reform Project of Taishan University (SZ202023) and the Teacher Education Research Special Project of Taishan University (JY-02-202022).

\section{References}

Akdemir, E., \& Özçelik, C. (2019). The Investigation of the Attitudes of Teachers towards Using Student Centered Teaching Methods and Techniques. Universal Journal of Educational Research, 7(4), 1147-1153. https://doi.org/10.13189/ujer.2019.070427

Bara, G., \& Xhomara, N. (2020). The Effect of Student-Centered Teaching and ProblemBased Learning on Academic Achievement in Science. Journal of Turkish Science Education, 17(2), 180-199. https://doi.org/10.36681/tused.2020.20

Gewin, V. (2020). Five tips for moving teaching online as COVID-19 takes hold. Nature, 580, 295-296. https://doi.org/10.1038/d41586-020-00896-7

Goldstein, H., Poole, C., \& Safko, J. (2005). Classical Mechanics. Beijing: Higher Education Press. 
Klein, P., Ivanjek, L., Dahlkemper, M. N., Jeličić, K., Geyer, M. A., Küchemann, S., \& Susac, A. (2021). Studying physics during the COVID-19 pandemic: Student assessments of learning achievement, perceived effectiveness of online recitations, and online laboratories. Physical Review Physics Education Research, 17(1), 010117. https://doi.org/10.1103/PhysRevPhysEducRes.17.010117

Komatsu, H., Rappleye, J., \& Silova, I. (2021). Student-Centered Learning and Sustainability: Solution or Problem? Comparative Education Review, 65(1), 6-33. https://doi.org/10.1086/711829

Ministry of Education of the People's Republic of China. (2018). Opinions on accelerating the construction of high-level undergraduate education to Comprehensively Improve Talent Cultivation Capacity. Retrieved from http://www.moe.gov.cn/srcsite/A08/s7056/201810/t20181017_351887.html

Nieminen, P., Hähkiöniemi, M., \& Viiri, J. (2020). Forms and functions of on-the-fly formative assessment conversations in physics inquiry lessons. International Journal of Science Education, 1-23. https://doi.org/10.1080/09500693.2020.1713417

Parrish, A. H., \& Sadera, W. A. (2018). Teaching Competencies for Student-Centered, One-to-One Learning Environments: A Delphi Study. Journal of Educational Computing Research, 57(8), 1910-1934. https://doi.org/10.1177/0735633118816651

Sintema, E. J. (2020). Effect of COVID-19 on the Performance of Grade 12 Students: Implications for STEM Education. Eurasia Journal of Mathematics, Science and Technology Education, 16(7). https://doi.org/10.29333/ejmste/7893

Usak, M., Masalimova, A. R., Cherdymova, E. I., \& Shaidullina, A. R. (2020). New Playmaker in Science Education: Covid-19. Journal of Baltic Science Education, 19(2), 180-185. https://doi.org/10.33225/jbse/20.19.180

Wang, S., Cui, L., \& Yan, X. (2020). "Student Centered" Teaching Reform and Practice for Linear Algebra. Frontiers in Educational Research, 3(1), 1-16. https://doi.org/ 10.25236/FER.2020.030101 (In Chinese)

Wu, A., Zhu, Z., \& Huang, D. (2019). From “Teachers Teach" to "Students Learn". Mechanics in Engineering, 41(5), 597-600. https://doi.org/ 10.6052/1000-0879-18-488

Xie, Y., Qiu, Y., Huang, Y., \& Wang, Q. (2020). Characteristics, Problems and Innovations of Online Teaching of "No Suspension of Classes" during the Period of Epidemic Prevention and Control. e-Education Research, 41(3), 20-28. https://doi.org/ 10.13811/j.cnki.eer.2020.03.003

Zhou, Y. (2018). A Course in Theoretical Mechanics. Beijing: Higher Education Press.

\section{Copyrights}

Copyright for this article is retained by the author(s), with first publication rights granted to the journal.

This is an open-access article distributed under the terms and conditions of the Creative Commons Attribution license (http://creativecommons.org/licenses/by/4.0/). 